\title{
on the popular and the critical Hop on Pop and the 'New Generation' of Cultural Studies
}

It is perhaps a little trite to deem a recently released book 'long-awaited'. However, Hop on Pop: The Politics and Pleasures of Popular Culture, edited by Henry Jenkins, Tara McPherson and Jane Shattuc, had been on the horizon of the international cultural studies community for several years before it finally went on sale in 2003. ${ }^{1}$ In Australia, a special issue of Continuum in 1999 heightened our anticipation; guest edited by Jenkins, McPherson and Shattuc, it showcased articles in the style of cultural studies that the anthology would seek to advance.

The Continuum introduction is deliberately provocative. It argues for a type of cultural studies that focuses on the context-specific particularities and meanings of the popular, and draws upon the close involvement of scholars with the cultures that they study. The editors state their belief that this 'new' cultural studies has the potential to become a political movement, initiating new alliances and dialogues among various academic and non-academic communities. ${ }^{2}$ Within this movement, they define the disciplinary role of (the then forthcoming) Hop on Pop as being to 'set the terms for future debates within and about cultural studies'. ${ }^{3}$

This review essay is an attempt to take up the call for such debates. It is, however, shaped by a particular set of interests to do with my position as an early career researcher for whom the questions of what cultural studies is and might become have certain implications. For me, reading Hop on Pop calls forth a different subject position than does reading many other field-defining anthologies. The difference is the volume's appeal to the present and its claim upon the future. It asks me to make something of the sense of discipline I have thus far developed as a student, and put it on the line to intervene in the issue of what kinds of cultural studies members of my generation might seek to develop. 
I came across the Continuum issue at the very beginning of my $\mathrm{PhD}$, and one or two of its ideas influenced my doctoral research. I was struck by the editors' flagging of Thomas McLaughlin's 1996 book, Street Smarts and Critical Theory, as one of the seminal works of the new cultural studies. ${ }^{4}$ In Street Smarts, McLaughlin shows how various subcultural communities reflexively produce 'vernacular' social theories that are shaped by the situated experiences and social locations of participants. In my doctoral work on the New Age, the vernacular theory approach helped me to appreciate the creative, problem-solving element in New Age thought that is easily overlooked in many a straight ideology critique.

Four years down the track, having now completed my PhD, I turned to Hop on Pop with a certain curiosity. I wondered about the extent to which I would come to identify with its 'project'. It is a large volume in the style of Cultural Studies edited by Lawrence Grossberg, Cary Nelson and Paula Treichler. ${ }^{5}$ Like the latter, it seeks to articulate a moment in the development of the discipline, but it has a more polemical edge-or at least its editorial framing does. The editors start off by making the bold claim that 'we are the first generation of cultural scholars to be able to take for granted that popular culture can be studied on its own terms, who can operate inside an academic discipline of cultural studies'. (3)

In two introductory essays, Jenkins, McPherson and Shattuc characterise and qualify the project. The crux of their position is that the study of popular culture requires new epistemologies and modes of expression —ones that eschew distant critical rationality, academic canons and the use of monolithic conceptual frameworks to analyse culture. (6) Instead of explaining the popular away in terms that make it grist for the academic mill, they propose that scholars take their cues from their subject matter and the kinds of insight that arise from intimate personal knowledge of it. Such an approach is not identified with a circumscribed set of methodologies. The golden rule is that scholars should not start with generalisations and then find details to fit, but should respect the details as found, and make generalisations only where warranted with the greatest of care. (16) Clifford Geertz's notion of thick description is singled out as a favoured way of writing about cultures, as is autobiographical writing, while the case study is praised as an academic genre that allows for portrayals of the complexities of cultural production, consumption and circulation. (7-14) Beyond this, in the absence of a clear definition, the idea of studying culture 'on its own terms' seems roughly to equate to the reiterated view that a superior critical position issues from immersion in the popular, and in particular from the kind of insights gleaned by a scholar who is also a fan or participant, and who thus has an inside working knowledge of localised meanings and rituals.

This is surely the kind of sentiment that would stoke the fires of those who, to borrow some Internet parlance, enjoy flaming cultural studies. Many criticisms of the discipline revolve around its supposed tolerance of subjective, impressionistic approaches to research. In their introduction to Cultural Studies in Question, a book that favours empirical research 
into the macroprocesses of culture, Marjorie Ferguson and Peter Golding point out the paucity of cultural studies' supposed 'doctrinal attachment to methodological eclecticism'. ${ }^{6}$ They reserve particular disdain for writing from personal history, a trend they identified as an ascendant part of a shift away from materialism towards questions of identity in cultural studies. Their fear is that 'This latest interest-shift sometimes comes dangerously close to establishing an intellectual autarchy, where autobiography can become its own auto-didactic method cum theory within a self-sufficient conceptual environment'. ${ }^{7}$

Given that Hop on Pop was under construction by the time Cultural Studies in Question was published, it seems quite feasible that the trends that Ferguson and Golding deprecate at least roughly equate to those that Jenkins, McPherson and Shattuc applaud. However, the latter have a justification for their personalised methodological particularism-one that is not directly concerned with large-scale structural processes or normative theories. The purpose of 'new epistemologies' is ostensibly to allow a form of accessible public intellectualism that achieves 'continued popular outreach'. (4) In this view, critics should be able to intervene in discussions about cultural practices in such a way that their analysis will have value for members of popular constituencies, helping them to reflect upon their own practices. This, according to the editors, is not to eschew the political, but to recognise its situatedness and the contingent forms of agency available to people active in cultures.

We are also told that the emergent approach is more than just an attempt to take popular culture seriously. The younger generation of academics is enjoined to make the case for their new ways of engaging with the popular to professional gatekeepers (including tenure committees). One of the intra-disciplinary functions of the volume and its manifesto is to help catalyse these expressed institutional processes of legitimation. (3) This desire for disciplinary approval perhaps explains the sometimes vague mix of polemic and qualification that makes up the 'manifesto for a new cultural studies'. It struck me that it contains very little naming of the enemy. A rather standard dig at the homogenising top-down determinism of Frankfurt School mass-culture critique is made in the companion essay, 'Defining Popular Culture'. $(31-2,38)$ Beyond this, however, neither introductory piece gives us much sense of whoespecially in terms of contemporary practice-is contributing to this cold, distant, elitist, reductive form of cultural analysis that functions as the Other for the 'new' type valorised.

The editors seem eager to avoid espousing a new foundationalism. This caution makes sense in a discipline that has historically defined itself more in terms of questioning orthodoxy than its realisation. Nonetheless, it makes for an oddly unprogrammatic manifesto. After conducting a tour of different developments in the field, the new cultural studies is depicted as a supplement to what went before, building on the best in the heritage rather than displacing it. The introductions end in what almost amounts to a moment of synthesis that irons out all previous contradictions. The new cultural studies is imbued with a resolve to go 
beyond previous dichotomies that have vexed the field, including 'British versus American cultural studies, critical versus affirmative analyses, modernism versus postmodernism, and ideological versus multipositional studies'. (40)

Such all-encompassing gestures left me with little formal sense of what I should expect as typical of the new cultural analysis, or as novel about it, when it comes to reading actual examples. While the introductions praised the broadly defined qualities of immediacy, multivalence, accessibility, particularity, contextualism and situationalism, they added the proviso that these are only non-exclusive 'family resemblances' found in the emergent cultural studies, and that there are no rules about how they are to be actualised or combined.

\section{- Personalising the popular}

So it was that I turned to the essays themselves. Around forty in total, they cover a wide range of topics in the realm of the popular and the everyday, though forms of popular entertainment are the focus of the majority. To give a thumbnail sketch of the veritable cavalcade of pop, we move from Oprah TV to TV Opera, by way of karaoke bars, red-light districts, computer-game worlds, op shops, nickelodeons, online forums, wrestling gyms, Star Trek conventions, jazz bars and the Tour de France. On the way we read Christian teen magazines, Gone with the Wind, stress management books, zines, milk cartons, nineteenth-century consumer journalism, baseball cards, Dr Suess, Uncle Tom's Cabin; we watch The Wizard of Oz, horror flicks, sci-fi, I Dream of Jeannie, Mae West, Tallulah Bankhead, soaps, Holocaust comedies, Canadian television and videos made by teenage girls about their lives; and we hear Morrisey and lo-fi. Most of the essays focus on a small number of primary texts, events or activities. They tend to combine description of microprocesses with interpretation of their significance for cultural politics. The familiar identity themes of race, ethnicity, gender, sexuality and youth dominate.

Thick description is certainly in evidence, and almost all of the essays include a scrupulous positioning of authorial self. We learn that most of the cultures studied are ones in which the critics have some kind of personal investment. In most of the articles about popular media, this translates into being an audience member or a fan of the texts studied. However, some pieces are less spurred by the writer's own previous experience of consumption, than by the way that certain forms of culture (in which they do not necessarily participate themselves) have significance for an aspect of their experience or identity. For instance, Eric Schaefer and Ethnie Johnson's study of an adult entertainment area in Boston is driven by their status as Bostonians with interests in the local press and urban planning. Likewise, when Tara McPherson discuses iconic literature of the southern USA, she speaks primarily as a southern US woman, rather than as a fan of Scarlet or Gone With the Wind. 
Having said this, I did not find that the personal element was integral to most pieces. What I mean is that while the writers tend to position themselves as having various kinds of personal stake in the study of a certain subject, their interpretation does not depend upon personal involvement. Rather than 'talking out of experience' leading to a different order of analysis, much of the research could have been undertaken by attentive, sympathetic outsiders. Most papers are well written, informative and pleasant to read. In varying ways, they go through standard procedures such as reviewing the secondary literature about a topic and relevant theories, isolating the key issues of discussion and exploring them through close attention to primary materials (mainly via textual analysis and ethnography). In many cases, the writer's affinity with the material might simply enhance their ability to undertake well-established forms of cultural research. For instance, none of the three papers that discuss computer games are 'techie' in tone. The writers investigate established new media theories and previous work on genre, narrative, colonialism and so on. One gets the impression that they are avid players, but this doesn't mean they draw upon arcane forms of knowledge that would be unavailable to a non-participant researcher who sought to acquaint themselves with gaming cultures.

There is, however, a significant minority of papers where the analysis revolves more closely around insights drawn from personal experience. They highlight how readings and, by extension, the politics of culture are contingent upon specificities of identity and social location. In her piece, 'Finding One's Way Home', Maria Koundoura explains how she used the US fantasy show I Dream of Jeannie as a tool to negotiate her sense of identity and difference as a child living in Greece, Australia and the USA alternately. The plot concept of a genie who comes from Baghdad, but lives in the USA, provided cues for Koundoura to explore her conflicted diasporic identity and later, as a cultural critic, to use this experience to unsettle cultural studies' traditions of appreciating 'the local'. In 'The Last Truly British People You Will Ever Know', speaking as a fan and a British child of Pakistani parents, Nabeel Zuberi explores his complex identifications with the imagined national communities projected in British pop music. Discussing the ambivalence about race in Morrisey's lyrics, he points out how irony functions as an exclusionary, implicitly white British cultural trope in a haltingly multiracial Britain. Both writers discuss the validity of the personal for cultural studies, showing how appealing to lived experience can be a way of interrogating generalising theories of culture. It can, according to Zuberi, 'point out their absences and elisions, and bring to voice neglected subjects'. (543)

However, Zuberi remains unsure about the broader role of individual life history in cultural studies: "For years I've anguished over whether "the personal" is valid in serious/academic criticism, pondering if writing my self is an indulgent exercise or justified because it has 
some typicality that can stand for something greater than the experience of a single individual/ subject'. (543) He acknowledges the limitations of the personal mode for attempting to understand the commonalities in experiences among people. (He also makes the interesting point that writing the self is more often undertaken by scholars who have already established their credentials through more objective types of research.) Arguably, Hop on Pop does include some essays that extrapolate from personal experience to reach conclusions beyond its purview. For instance, Elayne Rapping describes her and her daughter's responses to daytime soaps for women to make the argument that people do not read soaps realistically. She shows how the mix of dominant ideologies and feminist utopias in plots opens up discursive spaces to be investigated by viewers, who react to issues in complex ways. She argues that oppositional readings are as much a part of the pleasure of fandom, as is savouring utopian moments. While it is a highly intelligent piece that at least shows such critical readings to be possible, the question that remains unanswered is whether they can be taken as somehow representative of other viewers' readings. How could we know whether the critical literacies of an academic fan equate to those of other viewers and encourage them to make similar readings? Surely audience research is necessary to investigate such issues.

However, in the terms of the 'new cultural studies', it might be possible to argue that the value of an essay lies in its ability to cause other cultural participants to reflect on their readings. A number of contributions give the impression of being written for those who already have an advanced familiarity with aspects of popular culture, or with the experiences of a certain social group. There were many pop culture allusions that I did not get, and some writers seemed to assume the reader's general knowledge of the primary texts under discussion by not including expository conventions such as plot descriptions or biographies. Edward O'Neill's piece exploring possible camp readings of actress Tallulah Bankhead is one of these. It appears to be written for those who have previous knowledge of both discourses of camp and of Bankhead. But for every essay like this, there is one in which a scholarpractitioner scrupulously explains insiders' perspectives on culture for the benefit of a general reader. Stephen Duncombe's account of the creation of countercultural identities through zine production/consumption was the stand out example of this for me.

\section{- A new CRedentialism?}

Hop on Pop is a collection of fine essays that give personalised and particularistic accounts of popular culture through case studies, ethnography and textual analysis. However, it left me with doubts about whether it can and should be seen as emblematic of nothing less than a 'new cultural studies'.

One of my concerns is that, for a project that espouses the need for 'new epistemologies', there is little unpacking of what this might mean in terms of methodologies and theoreti- 
cal orientations. Indeed, the papers themselves include little methodological innovation or reflection on their discipline. The editors endorse so many previous tendencies in the field as to suggest that the 'new' cultural studies is a laissez-faire pluralism embracing anything so long as research is personalised, particularistic and conveys respect for the situated logics of the popular. However, what is left out of Hop on Pop combined with what is included signify a more circumscribed approach to culture than the editors' inclusive framing permits. The strong particularism espoused equates to what sociologists call 'methodological individualism', a view that takes a given cultural phenomenon as novel and freely created, rather than as something determined by a systemic social order (as in methodological holism). ${ }^{8}$ In terms of long-standing cultural studies themes about the nature of cultural production/ consumption, this places 'the new cultural studies' quite clearly in a culturalist trajectory that stresses the agency of participants to create meanings and change, compared with the structuralist view of cultural items as products of cultural reference systems.

Early British cultural studies was strongly influenced by European holistic social thought in the forms of structuralism and Marxism. As Graeme Turner puts it, 'One was required to think about how culture was structured as a whole before one could examine its constitutive parts'. ${ }^{9}$ However, at the same time, it tempered such traditions with culturalist arguments about localised meanings, the possibility of popular resistance to large-scale ideological systems and the view that culture is only partly determined by material relations (and in much more complex ways than those suggested by the base-superstructure model). Much of the subsequent history of cultural studies has been marked by negotiation of culturalist, structuralist and materialist tensions, with models (such as hegemony) that allow for a balance among them becoming influential in the discipline.

However, to perhaps court the kind of controversy the editors hedge against, I would argue that Hop on Pop is an attempt to reconstruct cultural populism and downplay the systemic dimensions of culture. This is not the stated mission, but saying as much would engage negative connotations deriving from critiques of previous forms of this tendency in cultural studies, and it would problematise the project's claim to 'newness' in the process. Many have noted the 1980s 'affirmative' populism, which, along culturalist lines, saw cultural consumption as an active process of meaning creation, often imbued with the power to resist and subvert dominant ideologies. ${ }^{10}$ Hop on Pop does not bear the previous populist mantra of resistance, but like its forbear it exalts the vox populi epistemologically and plays down the potential influence of the social conditions of production on culture.

With one or two exceptions, no attention is given to technology, the political economy of culture or cultural policy. For instance, Angela Ndalianis hardly mentions digital convergence and the vertical integration of media when she shows how computer games use and vary filmic conventions. Her thick description does not investigate the technological and 
economic influences on generic borrowing that comes as media content is distributed across platforms. In a way that is indicative of the collection as a whole, this approach cannot explain a cultural phenomenon as anything more than a tendency that has 'arisen' in the popular. The cultural studies of Hop on Pop is dominated by description of cultural items at the expense of explanations of how and why they are produced in certain ways and under the influences of larger-scale social, economic and cultural relations. I suspect that this sequestration is part of what is meant by popular culture 'on its own terms'. The focus is largely on the symbolic, on representation as a realm detached from sociocultural determinants.

There is certainly a place for papers like Ndalianis's. The problem lies in a framing that suggests that a collection of such pieces can be emblematic of cultural studies as an entire discipline. Highlighting the aporia inherent in extreme particularism, many of the papers draw upon macrological cultural models (such as Bourdieu, appeals to certain 'discourses' etc) or normative theories (such as the performance or overdetermination of identities) to shed light on the situated logics of the popular. In other words, even if sometimes to refute them, the authors depend upon the labour of researchers who do other kinds of work than situated 'readings', whose work is theoretical or conceptually isolates larger sociocultural patterns that cut across and influence a range of phenomena.

This also means acknowledging that the authors of Hop on Pop interpret the popular in terms of academic conceptual frameworks. Fan-critics may indeed be intimately familiar with the popular and appreciate the nuances, complexities, trade-offs, benefits, the sometimes paradoxical pleasures and politics that they experience as participants. But this does not mean that they have a privileged ability that allows them to know a culture 'on its own terms'. Dan Miller warns against the conflation of a desire to take culture seriously with an untenable belief that academics should take cultural expressions at face value. The latter, he believes, leads to a new form of positivism that sees the verbal legitimations of participants as a simplistic mark of their agency to create culture in their image. ${ }^{11}$ In fact, any participant has a specific limited perspective on, and role in fashioning, the interpersonal sets of relations through which culture is created and consumed-and how they may do so is influenced by social imperatives. The views of the participant-critic cannot be taken as representative of those of other participants. In particular, I wonder whether the critics in Hop on Pop are not precisely influenced by particular institutional discourses about 'taking the popular seriously' (and avoiding the bugbears of totalisation and determinism), which encourage them to find in the popular qualities that fulfil exogenous academic imperatives.

Cultural studies is richer for the insights of those who experience culture. However, it is highly reductive to reify the fan-critic position as though it were the proper one for the discipline per se. Non-participant researchers can also shed light on cultural consumption through the kind of audience- and qualitative interview-based work that is entirely missing 
in Hop on Pop. If cultural studies is to be truly relational, it needs to admit a range of voices and modes of knowledge into its conversations. Such a project cannot benefit from a new credentialism that privileges the authority of certain cultural studies intellectuals to speak on certain topics. It seems somewhat conservative to valorise only the intervention to those who have a personal investment in the culture studied. If nothing else, this is a recipe for largely positive readings of the cultural politics of the popular, as is the case with Hop on Pop. A discipline of cultural studies defined by such perspectives alone would be one analogous to political studies in which scholars can only comment upon the political cultures to which they belong, obviating democratic engagement among different groups on given topics. It would also contribute to the parochialism of cultural studies, further discouraging the study of areas of culture with which few researchers are personally involved.

Related to this is the way that the editors make popular entertainment a metonym for culture in general. It is interesting to note how previous anthologisers have resisted such a move. In their introduction to Australian Cultural Studies: A Reader, John Frow and Meaghan Morris assure us that 'cultural studies is not restricted to the study of popular culture'. ${ }^{12}$ Likewise, Grossberg, Nelson and Treichler state that 'One common misconception about cultural studies is that it is primarily concerned with popular culture'. ${ }^{13}$ Hop on Pop, however, reproduces the reduction, effectively excluding from the purview of the new cultural studies high, work and institutional cultures, and aspects of everyday life that are not given over to the popular. The repression of these other dimensions contributes to the sense that the popular is a largely autonomous sphere that, at most, bears incidental relation to institutional rationalities. By collapsing the cultural field into pop, it also denotes a further move away from class as a rubric for analysis.

It will probably be clear that, as a member of the 'new generation', and in spite of my own belief in the importance of 'listening to the vernacular', I remain unconvinced by the project of Hop on Pop - which I take to be a call for a cultural studies of restricted scope. At the same time, I hope that it is also clear that I like the book (which includes many excellent commentaries on aspects of popular culture), as distinct from the editorial framing that makes overly grand claims on its behalf. Jenkins, McPherson and Shattuc ask us to view the largely consumption-focused interventions of participant-critics about identity issues, via textual analysis of popular entertainment topics, as a template for cultural studies in general. However, as someone who inherits a cultural studies replete with methodologies, theories, modes of analysis and interdisciplinary influences, I find nothing in this to dissuade me from the view that a broader range of conceptual tools can be useful for intervening at different points and levels in the circuit of culture. ${ }^{14}$ 
GUY REDDEN teaches media and cultural studies at Lincoln University and recently completed a PhD at the University of Queensland. His research interests include new media, self-help, and conceptions of wellbeing in consumer culture.

1. Henry Jenkins, Tara McPherson and Jane Shattuc (eds), Hop on Pop: The Politics and Pleasures of Popular Culture, Duke University Press, Durham and London, 2002.

2. Henry Jenkins, Tara McPherson and Jane Shattuc, 'Introduction', Continuum: Journal of Media and Cultural Studies, vol. 13, no. 3, 1999, p. 11.

3. Jenkins, McPherson and Shattuc, 'Introduction', p. 6 .

4. Thomas McLaughlin, Street Smarts and Critical Theory: Listening to the Vernacular, University of Wisconsin Press, Madison, 1996.

5. Lawrence Grossberg, Cary Nelson and Paula A Treichler (eds), Cultural Studies, Routledge, London, 1992.

6. Marjorie Ferguson and Peter Golding, 'Cultural Studies and Changing Times: An Introduction', in Marjorie Ferguson and Peter Golding (eds), Cultural Studies in Question, Sage, London, 1997, p. xix.

7. Ferguson and Golding, p. xxvi.

8. Peter Hamilton, Knowledge and Social Structure: An Introduction to the Classical Argument in the Sociology of Knowledge, Routledge and Kegan Paul, London, 1974, p. 90.
9. Graeme Turner, British Cultural Studies: An Introduction, Routledge, London, 2002, third edn, p. 10.

10. Including Meaghan Morris, 'Banality in Cultural Studies', in Patricia Mellenamp (ed.), Logics of Television: Essays in Cultural Criticism, Indiana University Press, Bloomington, 1990, pp. 14-43; and Jim McGuigan, Cultural Populism, Routledge, London, 1992.

11. Dan Miller, 'Consumption as the Vanguard of History: A Polemic by Way of an Introduction', in Acknowledging Consumption: A Review of New Studies, Routledge, London, 1995, p. 51.

12. John Frow and Meaghan Morris, 'Introduction', in John Frow and Meaghan Morris (eds), Australian Cultural Studies: A Reader, Allen and Unwin, Sydney, 1993, p. xxii.

13. Grossberg, Nelson and Treichler, p. 11.

14. See Paul Du Gay, Stuart Hall, Linda Janes, Hugh MacKay and Keith Negus, Doing Cultural Studies: The Story of the Sony Walkman, Sage, London, 1997. Doing Cultural Studies cites an example of how a cultural artefact can be studied in terms of cultural identity, representation, production, consumption and regulation, each of which represents a dimension of the circuit of culture. 